Arqueología y Sociedad,

№ 22, 2010

\title{
EL CUERPO ORGANIZADO: SOCIOPOLÍTICA DE LAS REPRESENTACIONES ANTROPOMORFAS EN LA CERÁMICA PREHISPÁNICA DE VENEZUELA
}

Carlos Escalona Villalonga*

\begin{abstract}
Resumen
En Venezuela, las pocas investigaciones sistemáticas enfocadas en la figuración humana de la cerámica prehispánica han trabajado el problema de forma regional limitada para la esfera de interacción valencioide y el área andina. Por ello, mediante este trabajo, tomando como marco de referencia las piezas figurativas antropomorfas de las sociedades tribales igualitarias barrancoide-saladoide en el Orinoco y de las culturas tribales jerárquico-cacicales valencioide y Betijoque-Mirinday en la costa central y andes venezolanos respectivamente. Mediante la deconstrucción formal de las piezas para la definición de patrones figurativos, nos atrevemos a decir que las piezas antropomorfas en cerámica fueron, probablemente, poderosos vehículos utilizados por la sociedad para difundir identidades personales o comunales socialmente aceptadas y evidencian las relaciones de poder entre los individuos y su medio ambiente.
\end{abstract}

Palabras clave

Figuración antropomorfa, series barrancoide-saladoide, valencioide, estilos Betijoque-Mirinday.

\begin{abstract}
In Venezuela there has been little systematic research has focused entirely on the pre-Columbian pottery human figuration. They have worked on a regional problem limited to the Valencioid interaction sphere and the Andean area. Accordingly, by this work, using as a frame of reference the anthropomorphic figurative pieces egalitarian tribal societies Barrancoid-Saladoid in the Orinoco and tribal cultures and hierarchical cacicales Valencioid Mirinday Betijoque-central coast and in the Venezuelan Andes, respectively. We considered an inquiry by way of comparison between different periods, regions and / or culture from body theory in archeology. Through formal deconstruction of parts for the definition of figurative patterns, dare we say anthropomorphic ceramic pieces were probably powerful vehicles used by the company to spread personal and communal identities and reveal socially accepted power relations between the individuals and their environment.
\end{abstract}

\section{Keywords}

Human figuration, barrancoid-saladoid series, valencioid, Betijoque-Mirinday styles.

* Antropólogo - Universidad Central de Venezuela.

Correo electrónico: syahoram@gmail.com 


\section{ESRUEMA DE ORGANIZACIÓN SOCIOPOLÍTICA DE SOCIEDADES PREHISPÁNICAS DE VENEZUELA}

Se han propuesto dos esquemas clasificatorios generales para las culturas prehispánicas del país. El primero fue propuesto con Cruxent y Rouse (1958), esta presenta tres periodos para la época prehispánica (Paleoindio, Mesoindio y Neoindio) y uno para el periodo postcontacto (Indohispano). El término Paleoindio está relacionado a "la etapa de desarrollo de la cultura del indio americano en la que el principal medio de subsistencia era la caza, siendo los artefactos principales, artefactos de piedra desbastada y, en especial, las puntas de proyectil usadas para cazar" (Cruxent y Rouse 1958: 83). Es una época que comienza antes del periodo I definido por Cruxent y Rouse, vivieron en condiciones climáticas muy diferentes a la actuales y su modo de subsistencia principal era la caza de megafauna (mastodontes, megaterios, etc.) y la recolección de plantas pero en un grado mucho mas bajo.

La época Mesoindia equivale al periodo I propuesto por Rouse y Cruxent (1963) en su cronología relativa y finaliza alrededor del año 1000 a.C. con la aparición de la agricultura intensiva y la cerámica en Venezuela. El término Mesoindio denomina una época cuya economía se basa en la pesca, la caza (de animales mas pequeños que en el Paleoindio) y la recolección. Se caracteriza por la presencia de artefactos de piedra pulida, de lascas y de concha (Tarble 1988: 232), siendo estos últimos una innovación tecnológica de esta época. Representa una etapa de transición entre el Paleoindio y el Neoindio. Los Mesoindios que se encontraban lejos de la costa sobrevivían cazando mamíferos pequeños y recolectando plantas mientras que los Mesoindios de la costa cambiaron en una forma de alimentación basada en la pesca y recolección de mariscos. Como resultado se encuentran grandes concheros donde las puntas de proyectil están prácticamente ausentes y en su lugar hay puntas de hueso, gubias, copas, conos, etc., todos hechos de conchas de mar y huesos de pez (Rouse y Cruxent 1963: 48). Una importancia innegable de la explotación marina como recurso para subsistir es que acercó a los Mesoindios al mar, se familiarizaron con el y, aparentemente, adquirieron la navegación, lo cual permitió la ocupación de las islas cercanas a la costa. Rouse y Cruxent (1963: 50) describen cuatro patrones de vida que pudieron existir en Venezuela durante la época Mesoindia:

a) Los sobrevivientes Paleoindios: como bien el nombre lo indica fueron los que continuaron con el modo de vida Paleoindia, con puntas de proyectil muy parecidas a las halladas en el complejo Las Casitas, raspadores y martillos de piedra, etc.

b) Los pescadores costeños: ya descritos en los párrafos anteriores.

c) Los recolectores tierra adentro: también descritos anteriormente. Debían consistir en bandas nómadas o seminómadas. Pudiesen estar asociadas a un tipo de material limitado que permitiera su subsistencia y su movilidad.

d) Los agricultores incipientes: de los Mesoindios que vivían alejados de la costa, de la recolección de vegetales silvestres debieron adquirir la agricultura incipiente a finales de la época Mesoindia (Rouse y Cruxent 1963: 50).

El Neoindio se distingue por una vida sedentaria con la aparición de la alfarería y la agricultura intensiva se convierte en el medio de subsistencia por excelencia. Las dos fuentes más probables de domesticación de plantas serían el maíz y la yuca (Sanoja 1981). Como podemos notar, Cruxent y Rouse no prestan interés alguno a la organización sociopolítica de las culturas correspondientes a cada una de estas épocas, sino, al grado de desarrollo tecnoeconómico de estas. El modo de vida tribal igualitario es dividido por la autora en tres sub modos según su forma de producción: vegecultora, semicultora o mixta. Estas etapas o modos de vida se presentan, en el texto de Vargas, como subsecuentes o como consecuencia del anterior. La autora mantiene la visión evolucionista cultural de Morgan y de Service, sin embargo, no considera su es- 
quema como general o universal, sino regional, es decir, para el caso exclusivo de Venezuela y algunas áreas en el Caribe (Sanoja 2006). Si bien para Vargas, al igual que para Cruxent y Rouse (1958), los cambios tecnoeconómicos y de producción son la base para proponer estos modos de vida, cada uno de estos tiene asociado una forma o manera de organización sociopolítica, desde la mas incipiente a la mas compleja, es decir, de lo igualitario, a lo jerárquico hasta el clasismo.

\section{Modo de vida igualitario de recolectores cazadores}

Este modo de vida se fundamenta en la extracción y transformación, de manera colectiva, de materias primas bajo una forma cooperativa, así se hacía más eficiente la apropiación y distribución de los recursos naturales que garantizan la supervivencia y reproducción social:

La reciprocidad, el compartir, las formas de cooperación, con las formas básicas como la sociedad resolvía la precariedad de la producción, los riesgos permanentes a los que estaba expuesta cada unidad domestica, cada individuo. Se originó de esta manera una dicotomía en el campo de las relaciones interespecificas donde podía coexistir el individuo como organismo natural o como sujeto de relaciones sociales (Sanoja 2006: 28).

Las relaciones sociales, como consecuencia de lo anterior, eran reguladas por el sistema de parentesco siendo de carácter colectivo y reciproco. Vargas (1990: 105), aclara que el término igualitario no implica en negar de cualquier forma de poder o digresión, sino en la manera cómo ese poder afecta a los llamados aspectos esenciales o fundamentales, o sea, aquellos referidos al régimen de propiedad, relaciones de producción, distribución, etc. Las bandas integrantes de esta formación económico social practicaban la reciprocidad "como mecanismo [social] que compensaba la precariedad de la producción" (Vargas 1990: 94). Este mecanismo permitía a cualquier miembro de la banda disponer de los recursos de los demás y viceversa, el cual no desaparece al comienzo del modo de vida tribal sino que se fortalece:

La apropiación de los alimentos en los cazadores supone la existencia de una producción y un consumo subsistenciales; con la sedentarización existe la tendencia a reducir la producción constante que se requería por la falta de control sobre la producción biología de las especies. Esto permite que los grupos comiencen a realizar otros procesos de trabajo distintos a los subsistenciales; en suma, se observará un desarrollo y diversificación de las prácticas sociales (Vargas 1990: 95).

La disolución de esta formación económico social fue resultado del predominio de prácticas productivas, como lo son la ganadería y la agricultura, sobre las prácticas apropiadoras características de estos grupos. Esto, trajo como consecuencia la formación de aldeas, el inicio del sedentarismo y el crecimiento poblacional.

\section{Modo de vida tribal igualitario}

La tribalización de los cazadores y recolectores implicó la complejidad social con dos propósitos, por un lado, garantizar la producción y por el otro, garantizar la propiedad y el proceso de producción. El sedentarismo determinó que la recolección y la apropiación no fuesen suficientes para mantener el crecimiento constante de la sociedad luego de la estabilización territorial. Los cambios durante el proceso de tribalización, en relación al modo de vida igualitario de recolectores cazadores, suponen un desarrollo en la eficacia y las funciones de instrumentos y medios de producción. Un establecimiento de los procesos de producción de alimentos, crecimiento sostenido de la producción y todos aquellos factores que suponen la reproducción (en mayor medida) del grupo social. Ampliar y diversificar la producción, es decir, la necesidad de producir un plusproducto (Vargas 1990; 100). No había diferencias entre el productor primario y el con- 
sumidor, ni tampoco existe una planificación social del trabajo.

Así tenemos cambios en el régimen de propiedad porque, si bien sigue siendo colectiva, ahora son propietarios objetivos de los medios naturales de producción como objeto de trabajo; presencia definitiva de aldeas como base física de las unidades sociales; un surgimiento de complementariedad económica entre aldeas, lo cual, implica el intercambio tanto de materia prima como de materiales manufacturados (Vargas 1990; 100); relaciones sociales basadas en el parentesco que progresivamente se transforman hasta devenir en políticas o de subordinación; la reciprocidad esta restringida ahora a la tribu y supone el compromiso entre grupos para asegurar la propiedad y la fuerza de trabajo se controla dentro de un mismo grupo de parentesco (Vargas 1990: 100-1).

\section{Modo de vida tribal jerárquico-cacical}

Este modo de vida surge producto de las contradicciones en el modo de vida tribal igualitario cuando se hace más difícil compatibilizar la coparticipación de todo el colectivo en las decisiones sobre el ordenamiento del proceso productivo y en la distribución de los recursos y de la propiedad colectiva, por ello, fue preciso el surgimiento de una estructura social jerarquizada que mantenía el control del trabajo y del conocimiento (Sanoja 2006: 37). Vargas (1990: 108), aclara que el término cacical no es sinónimo de la presencia de un cacique sino de la existencia de una institución que cumplía con funciones similares a las que ejercieron los caciques. El modo de vida cacical no solo existió en lugares donde se dieron cacicazgos o jefaturas, sino también donde existió una estructura social desigual, concretada en patrones de distribución diferencial para los distintos sectores de la población, prestación de servicios, etc. El modo de vida tribal jerárquico-cacical supone trasformaciones importantes de los patrones de distribución y cambio, alterándose el sistema de acceso colectivo a la producción. La transformación de las relaciones de parentesco en políticas surge como consecuencia del crecimiento de una aldea sobre el resto, lo cual, afecta los patrones de complementación económica, esto fue factible por la existencia de un mayor desarrollo de as fuerzas productivas en donde hay que considerar, de manera importante, la fase física o medio ambiente donde tal aldea se desarrolla y el carácter de sus modos de trabajo (Vargas 1990: 101).

Estos cambios se objetivan en la existencia de una aldea central, la cual asume el papel de sede de un poder político, religioso, administrativo y, eventualmente, manufacturero. Así mismo, comienza a existir apropiación de sobretrabajo de otras aldeas bajo la forma de "tributos" (Vargas 1990: 101). En este modo de vida algunos individuos se liberan del rol primario de productores y pasan a ocupar su tiempo en el procesamiento de materias primas (artesanos) o a distribuir los bienes manufacturados. Esto último implica el surgimiento de rangos, estamentos o jerarquías dentro de la estructura social, los cuales, probablemente, eran hereditarios (Vargas 1990: 101). El status social de los dirigentes se ve acompañado de un patrimonio, lo que implica la separación, dentro del patrimonio colectivo, de uno reservado sólo para estos grupos; esto genera una institución que legitima la desigualdad social y permite que el plusproducto adquiera carácter de excedente de producción (Vargas 1990: 101-2).

\section{Modo de vida clasista inicial}

Una vez distribuida de manera territorial y altitudinalmente desigual los recursos, la necesidad de coordinar el trabajo y la desigualdad social, fue necesario ejercer control territorial sobre la fuerza de trabajo, surgiendo así las clases sociales y su expresión política coercitiva: el Estado (Sanoja 2006: 37). No haremos el mayor énfasis en este modo de vida debido a que en Venezuela no existieron sociedades estatales como en el caso del Perú y México. En este modo de vida se puede observar que adquiere importancia cen- 
tral la diferencia entre la producción primaria y el surgimiento de una clase gerencial. Como consecuencia de lo anterior, existe la presencia de especialistas encargados de estudiar los ciclos naturales. La gran intensificación agrícola es consecuencia del surgimiento de estos especialistas (Vargas 1990: 102). La agricultura intensificada, genera un plusproducto, pero a diferencia del modo de vida anterior, este se transforma en excedentes y crea la necesidad de una institución que regule su apropiación por parte de una clase. En suma, se produce la división social del trabajo que genera la existencia de dos tipos de trabajadores, los especialistas agrícolas que manejan procesos técnicos cada vez más complejos, y los trabajadores del campo o productores directos (Vargas 1990: 102). Estos modos de vida propuestos por Vargas nos servirán como guía para la interpretar los modos de representación corporal de las series barrancoide-saladoide, valencioide y los estilos betijoque-mirinday.

\section{INTRODUCCIÓN A LA FIGURACIÓN ANTROPOMORFA PREHISPÁNICA DE VENEZUELA}

En Venezuela, la figuración antropomorfa cerámica es tan antigua como el propio origen de las culturas formativas, e incluso, anterior. Con el surgimiento de la sociedad tribal agrícola, período conocido como Neoindio, gran cantidad de culturas regionales aparecen desde 1000 años a.C. Este periodo Formativo introduce dos innovaciones tecnológicas que cambian las formas de organización social: la agricultura y la cerámica. Desde estos inicios alfareros, la representación antropomorfa estuvo presente en el repertorio de las manifestaciones culturales venezolanas en cerámica. Aún cuando lo que caracteriza a este período es la integración de la figura humana a la forma total de la silueta de las vasijas, también estuvieron presente, escasos pero elaborados y representativos ejemplos de figurinas. El Orinoco medio y bajo (Navarrete 1999) jugaron un papel nodal en el proceso temprano de formación de sociedades agroalfareras, como lo demuestran las evidencias de las tradiciones vegecultoras saladoide y barrancoide cerca de 1000 años a.C., quienes introdujeron una rica herencia cultural amazónica, posiblemente arawaka. Estas sociedades, especialmente la barrancoide, desarrollaron un tipo de representación antropomorfa modelada-incisa representada en dos modalidades. Por un lado, rostros y extremidades adosadas a las paredes de voluminosas y pesadas vasijas, las cuales se extendían de forma escultórica a lo largo de la toda la superficie externa del recipiente.

En otro extremo de la dicotomía cultural venezolana, en la región de Lara, se desarrolló otra cultura formativa semicultora, la tocuyanoide. La representación antropomorfa de esta sociedad, de manera similar a la orinoquense y con escasos ejemplos de figurinas, integra la figuración humana a grandes recipientes y urnas funerarias, en los que rostros humanos se fusionan con elementos animales, especialmente de ranas y serpientes. De la misma manera, al menos 600 años a.C., la costa occidental del Lago de Maracaibo y los Andes Septentrionales venezolanos (Wagner 1999) estaban habitados por grupos fabricantes de alfarería pintada polícroma y modelada-incisa en Zulia (Arvelo 1999), relacionados con Lagunillas (400 años a.C.) y La Pitía (10 años a.C.), quienes siguieron de manera general el mismo patrón de representación antropomorfa.

Otras tradiciones andinas como la de Santa Ana, tentativamente relacionada con la esfera tocuyanoide, generaron figurinas muy elaboradas como la conocida Fumadora, en las que individuos representados de manera muy realista, por medio del modelado-inciso y la pintura polícroma curvilínea, parecían realizar actividades rituales sentados en banquillos o dúhos. Un caso particular también lo definen tradiciones como la Betijoque, en la que las figurinas -femeninas, masculinas y asexuadas- se presentan con frecuencia complementadas con decoraciones plásticas y pintadas que parecen representar pinturas corporales, accesorios e indumentarias. Durante el primer milenio de la era cristiana se consolidan las tradiciones existentes, surgen nuevas y comienzan a romperse los límites geográfico-culturales. La tradición osoide en Bari- 
nas, la ocumaroide en la costa centro-occidental y la arauquinoide en los llanos centro-orinoquenses, dan cuenta de la introducción en los llanos y costas venezolanos de nuevos grupos -como los caribes amazónicos- y del surgimiento de tradiciones culturales más locales.

Podríamos atrevernos a plantear que este período representa el inicio de la desvinculación de la figuración antropomorfa de la silueta de las vasijas para convertirse en una representación independiente en forma de figurinas. Aunque continúa la integración figurativa humana en las vasijas, cada una de estas nuevas sociedades comienza a producir con más frecuencia figuras de arcilla con rasgos estilísticos diagnósticos y diferentes que representan individuos con diversos atavíos y características corporales. Aún cuando la posición parada, el predominio de fi-

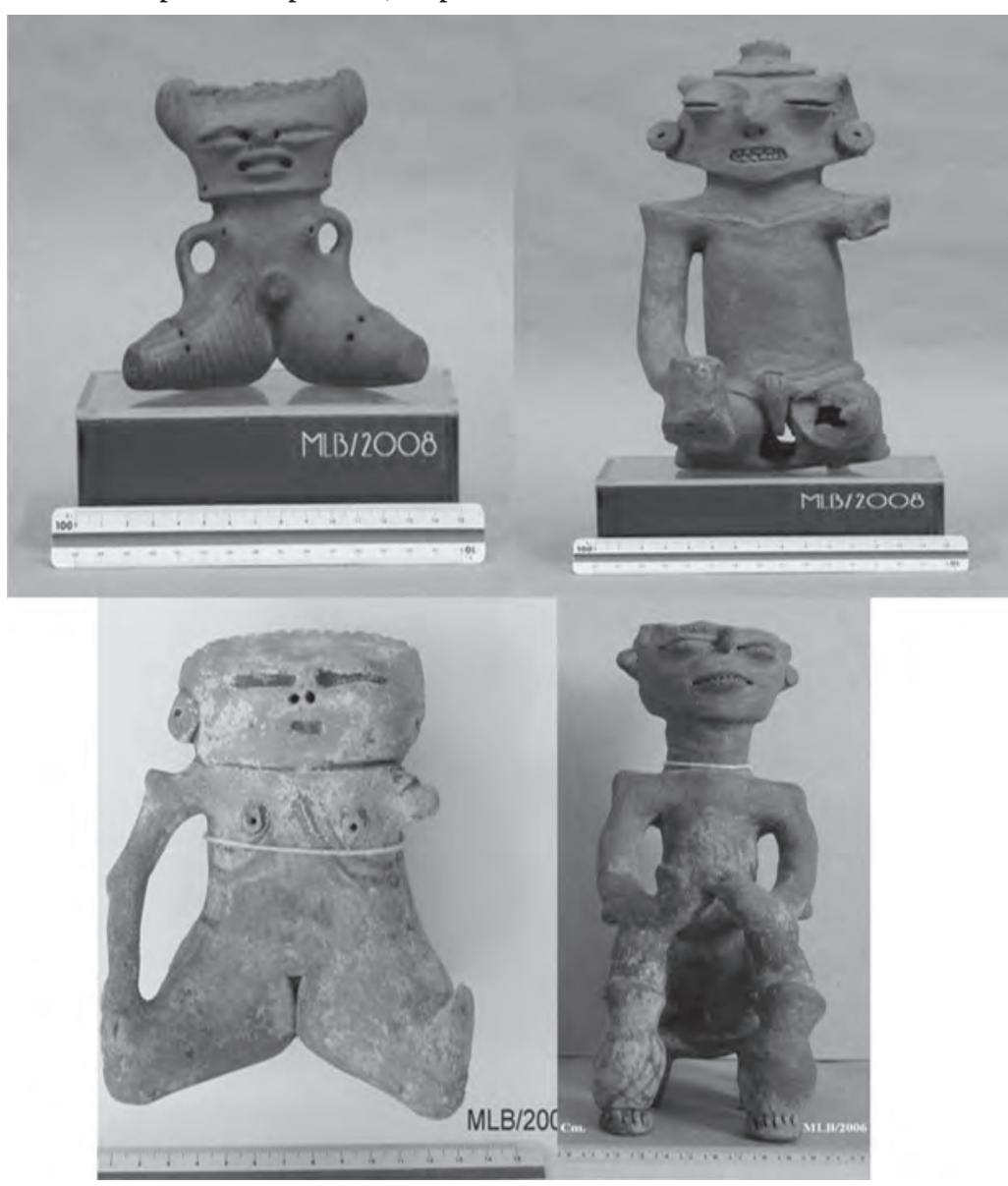

guras femeninas desnudas con resaltantes rasgos sexuales -glúteos, vagina, senos- y el uso del motivo de grano-de-café para representar ojos -y ocasionalmente bocas o vulvas-, son rasgos estilísticos comunes, cada cultura desarrolló un patrón decorativo distinto.

Por ejemplo, en el caso arauquinoide, los rostros, tanto aquéllos adosados a grandes vasijas como los pertenecientes a cabezas alargadas de figurinas, son realizados con una compleja combinación aplicada-incisa-punteada, en la que unos alargados e inclinados ojos grano-de-café bajo alargadas y finas cejas aplicadas -frecuentemente punteadas- se unen en una pequeña nariz y se ubican sobre minúsculas bocas grano-de-café, motivo facial coronado por una banda incisa de triángulos rellenos de puntos. En el caso osoide, las cabezas tienden a ser ovaladas, los ojos granode-café pueden presentar punteado en su ranura y los otros rasgos faciales -cejas, boca, etc.- son más burdos; por otro lado, la presencia de pintura lineal o total tanto en los cuerpos como en las cabezas las caracteriza. A partir del primer milenio d.C. se comienza a diluir la diferencia cultural oriente/ occidente y surgen grupos jerárquicos cacicales a partir de los semicultores occidentales. La sedentarización en áreas con recursos abundantes, diversos y predecibles, propició la concentración y aumento demográfico, estimuló el desarrollo de la complejidad sociopolítica y cultural. La religión tribal animista, ya desarrollada desde el

Figuras antropomorfas de los Andes venezolanos. Estilos Betijoque y Mirinday. 
Formativo, reflejó la relación social con el ambiente e intenta explicar y dominar las actividades sociales y productivas a través del chamán, pero es posible que las élites política y religiosa comenzaran a tomar mayor prominencia dentro de los sistemas rituales y de culto.

Los arauquinoides, en los llanos occidentales desde cerca de 300 d.C., se movilizaron agresivamente entre 600 a 700 d.C. al Orinoco Medio (Navarrete 1999). Posteriormente, alrededor de 1100 años a.C., influyeron la costa central y área del Lago de Valencia forjando la compleja y rica cultura valencioide, la cual controló parte de la costa central -desde Tucacas a Río Chico- y territorios insulares como Los Roques (Antczak y Antczak 2006). Probablemente por la presión Caribe en el Orinoco, barrancoides y saladoides se movieron hacia las costas. En la costa central y área de Valencia, los barrancoides se unieron posiblemente a protoagricultores locales, expresado en la cultura La Cabrera, y en la costa oriental, barrancoides y saladoides con grupos costeros formaron el saladoide costero. Esta nueva diversidad cultural venezolana generó diversificadas modalidades de trabajo y estructuras sociopolíticas jerárquicas cacicales. Entre estas culturas están las noroccidentales y andinas de los estados Zulia, Falcón, Lara, Trujillo, Mérida y Táchira, en general asociadas a tradiciones tierroide y dabajuroide, los complejos sitios monticulares osoides en los llanos altos barineses y la expansiva cultura norcentral valencioide. La centralización cacical permite redistribuir el excedente productivo y profundiza la especialización del trabajo. Ciertos individuos se distancian de la producción primaria y se dedican al trabajo artesanal, a la redistribución de bienes manufacturados, a coordinar y controlar actividades sociales y a suministrar servicios de orden gerencial y/o simbólico. Su papel social, diferente al del productor primario, implica el surgimiento de rangos y jerarquías en la estructura social. El rango, aún asociado al parentesco y la descendencia, inicia un control social diferenciado por parte de los dirigentes y, por lo tanto, un acceso privilegiado a los bienes y al producto colectivo por parte de caciques y chamanes.

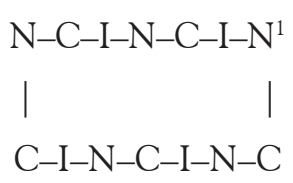

La representación antropomorfa temprana en el Orinoco y costa central y oriental de Venezuela.

Si bien estas sociedades se pueden definir por sus restos arqueológicos como entidades independientes y diferenciadas, luego del análisis de las piezas antropomorfas saladoides y barrancoides podemos notar que, aunque hay diferencias tecnológicas en la cerámica, existe similitud en la representación corporal presente en estas. Esto puede corresponder a una transmisión de elementos estéticos entre ambas tradiciones, lo que refleja la existencia de contactos entre las dos sociedades y trae como consecuencia cierta compatibilidad figurativa pero conservando diferencias identitarias, en su mayoría tecnológicas y decorativas, mas no figurativas.

Dicha compatibilidad podría responder dos razones, una hermandad pantribal entre estos grupos orinoquenses tempranos o a pool genético cultural, es decir, un origen ancestral común (Navarrete 2006). Las hermandades pantribales son definidas por Kottak (2003) como "aquellas que se extienden por toda la tribu abarcando varios poblados [las cuales] tienden a darse en áreas donde entran en contacto dos o más culturas diferentes" (p. 139). Generalmente, estas se crean en tiempos de guerra pero consideramos que, aparte de esto, y de intercambios comerciales, dichas hermandades cumplieron un rol importante en la posterior compatibilidad estética y probablemente religiosa de los grupos saladoides y barrancoides. Como menciónanos en las primeras páginas de este capitulo, Navarrete (2006) y Delgado (1989), consideran estas culturas o hermandades orinoquenses como animistas. Para las sociedades de pensamiento

1 Hace referencia a la relación hombre-naturalezacultura, donde $\mathrm{N}=$ naturaleza; $\mathrm{C}=$ Cultura; $\mathrm{I}=$ Individuo 


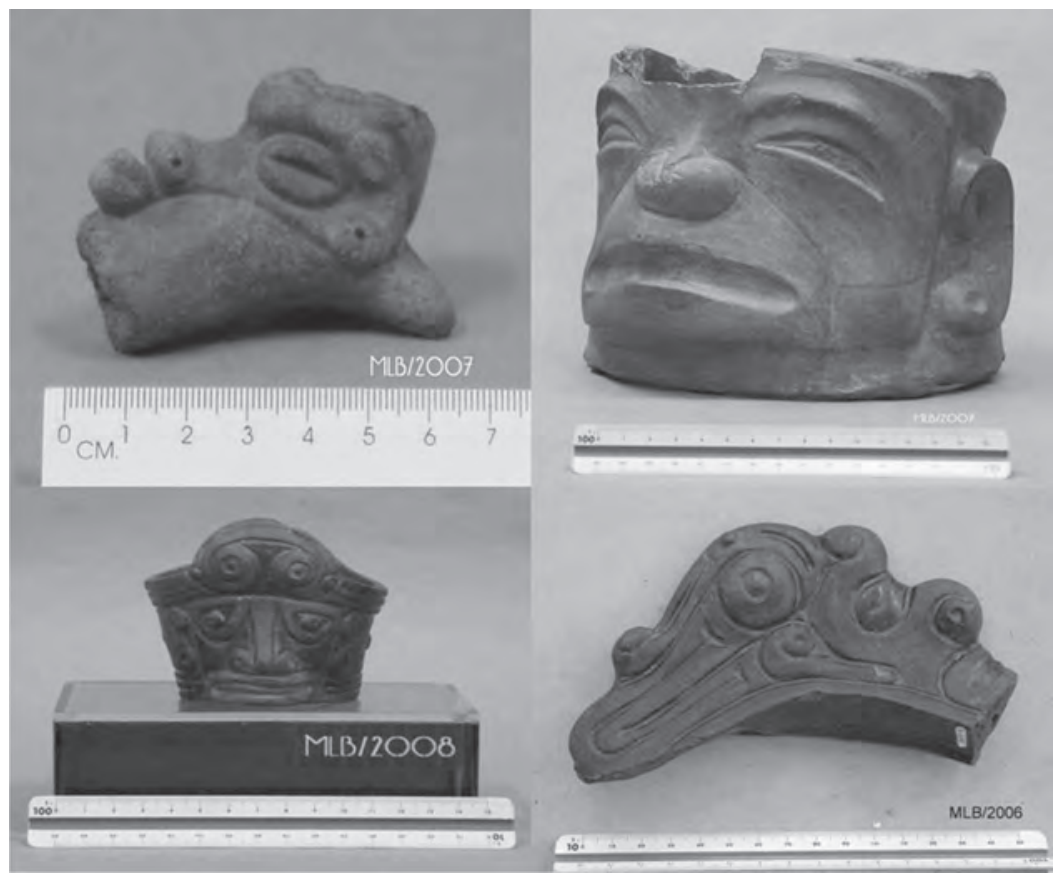

Figuras antropomorfas del Orinoco y Costa Central. Serie Barrancoide.

turalmente mediante la alfarería creando una estrecha relación entre el individuo, la naturaleza y la cultura (I-N-C), poseyendo la última las características de los primeros. Algo similar ocurre en el totemismo donde, "la cultura se concibe como una proyección de la naturaleza y hace las veces de bisagra entre la sociedad" (Levi-Strauss 1964: 177). Sin embargo, no estamos proponiendo animista "el mundo es como una unidad cerrada, en la que cualquier objeto, animal o planta (...) está regida por fuerzas ocultas (...) todo lo que existe, y particularmente todo lo que es móvil, encierra un alma dotada de poder (Delgado; 1989: 71). Esta visión del mundo es inseparable de su representación física, lo cual se entiende como una mediación simbólica entre el hombre, la naturaleza y la cultura, estas últimas cargadas de un ánima. Vargas (1985 en Delgado 1989), propone que las sociedades que presentan un modo de vida igualitario tribal, tienen como principal contradicción la relación hombrenaturaleza y no hombre-hombre, por ello las respuestas fenoménicas que están ligadas a la superestructura reflejan dicha contradicción. En consecuencia, en estos grupos sociales, en concordancia con Delgado (1989):

...la relación hombre naturaleza debió adquirir una importante significación y ella permitió la materialización de una alfarería cuya resolución formal tiende a la representación de modelos naturales sacralizados (p. 72).

Es decir, la naturaleza es pensada como mundo social, o viceversa, representada culque los grupos barrancoides y saladoides eran totémicos, pero la relación I-N-C funciona, probablemente, bajo el mismo principio. Esta propuesta surge de la profusa y variada producción de apéndices en los que cabezas humanas se sobreponen y mezclan con otras figuras zoomorfas -aves, felinos, serpientes, monos, etc.- y probablemente también fitomorfas que comprenden parte del mundo natural, produciendo un efecto barroco, en el sentido de saturación de significados, dual y ambiguo. Esto ultimo trajo como consecuencia que, al momento de decostruir las piezas, fue difícil distinguir cuerpo de decoración debido a que, la interpretación cultural del cuerpo está frecuentemente muy imbricada con la representación anatómica natural. Por ello, nuestra propuesta supuso una interpretación metodológica que separa, solo con fines clasificatorios, elementos corporales de otros incorporados. En consecuencia, da la impresión que cultura, hombre y naturaleza fuesen una misma cosa en el objeto, es decir, no existe una división clara entre ellos, el cuerpo (humano) se concibe como parte del espacio natural (animal y vegetal). Se humaniza la naturaleza y se naturalizan las acciones sociales. 


\section{Figuras antropomorfas del Lago} de Venecia. Serie Valencioide.

Entonces, podríamos considerar que el sistema de las funciones sociales corresponde a lo natural y éste al mundo de los objetos (Levi-Strauss 1964: 188), por tanto, el medio ambiente y alfarería son dos conjuntos mediadores utilizados por estos grupos para transformar la contradicción entre ellos y la naturaleza y poder pensarlas (o pensarse) como una totalidad donde los limites del ser social no están claros. Esta relación hombre-naturaleza-cultura se presenta de tres modos en nuestra muestra. Como la representación del alter ego (Antolinez 1941; Delgado 1989) en piezas donde se representa un rostro humano en las paredes del plato y en el borde dos apéndices con forma de reptil. También como figuras duales, donde se presentan dos rostros iguales, viéndose el uno al otro o viendo cada uno hacia un lado diferente respetivamente. Por ultimo, como recipientes efigie donde el cuerpo de la vasija (en este caso una urna) y el cuerpo humano son la misma cosa. Si bien posteriormente estos grupos se expanden hacia la costa central u oriental, Lago de Valencia y zona insular de Venezuela complejizándose (Navarrete 2006: 273), no existe una separación del cuerpo humano de la totalidad y funcionalidad de la vasija. La negación del hombre como parte de la naturaleza comienza en tradiciones más tardías y estratificadas como Betijoque donde, la relación hombre-hombre se convierte en la contradicción principal mediante representaciones corporales y simbólicas que proporcionan un modelo de diferenciación entre ellos y la naturaleza. Sin embargo, la estratificación social no implica una necesaria separación entre los individuos y la naturaleza.

Aparentemente con la estratificación social dentro de esta cultura, comienza a resaltarse el papel individual de los sujetos, lo que trajo como consecuencia una gran producción de figuras independientes antropomorfas. Al igual que las tradiciones orinoquenses, realizaron vasijas efigie y figuras duales. Sin embargo, esta dualidad no implica la humanización de la naturaleza o viceversa. Estas figuras se presentan como entes diferenciados dentro del mismo objeto, por ejemplo, doble efigies mitad humano, mitad primate, con apéndices zoomorfos y antropomorfos a un lado del rostro, e incluso representaciones

2 Hace referencia a la relación feminidad-naturaleza, donde $\mathrm{F}=$ Femenino; $\mathrm{A}=$ Animal; $\mathrm{V}=$ Vegetal. 
posiblemente fitomorfas en la panza de la vasija figurativa. Estos elementos naturales cumplieron un papel vital en los ámbitos productivos y ceremoniales. No es casual que estos elementos no se representan juntos, es decir, no hay piezas efigies que presenten apéndices zoomorfos y antropomorfos o zoomorfos y fitomorfos. Probablemente no sólo ocurre una separación del hombre con la naturaleza, sino también entre los elementos naturales (vegetales y animales). En general, dentro de su gran heterogeneidad formal, sus representaciones, mayoritariamente femeninas, consisten en figuras humanas desnudas en las que se resaltan rasgos corporales de silueta como pies, piernas bulbosas, glúteos, genitales, brazos y manos (con frecuencia arqueados colocados sobre la cintura o sosteniendo la cabeza) y cabezas hipertrofiadas que adquieren volúmenes ovalados o naviformes. Estos iconos femeninos atestiguan la importancia del signo y la magnitud simbólica dentro de esta sociedad y subyacen en ellos definiciones estéticas de la visión del mundo valencioide. Para Delgado (1898):

...la importancia de la mujer debió permitir la formulación de mediaciones simbólicas propiciadoras, que debieron expresarse en las múltiples objetivaciones de la conciencia social, en los mitos, en las ceremonias destinadas a la magia y seguramente se manifestaron en las formas particulares que adquieren las derivaciones sensitivas y sensoriales como representación de los modelos estéticos, que en estas sociedades parecieran demostrar un alto grado de convencionalización (Delgado 1989: 133).

Aún cuando los cuerpos están desnudos y no poseen decoraciones pintadas que sugieran indumentaria o pintura corporal, algunas presentan bandas inciso-punteadas en sus rostros o cuellos que podrían interpretarse como escarificaciones y collares. En el rostro, en ocasiones, se observan incisiones sobre las mejillas, labios y cejas, así como perforaciones en sus orejas y bandas en sus frentes que aluden a cierto tipo de decoración corporal. Dicha decoración implica una modificación de la naturaleza del cuerpo humano, infringiéndole cambios culturales permanentes e irreversibles como, por ejemplo, las escarificaciones y la deformación craneal.

Por otra parte, se encuentran piezas que no presentan representación genital, es decir, se presentan asexuadas. Sin embargo, comparten las mismas características corporales que las figuras femeninas, se presentan sedentes y de pie, efigies y apéndices; todas aparentemente desnudas. La desnudez y la feminización de las figuras asexuadas se podrían asociar a que, siendo la mujer productora y reproductora a partir de su propio cuerpo, mediante "su fecundidad, un sincretismo las une simbólicamente con la reproducción de la vida animal y vegetal" (Delgado 1989: 132). Sin embargo, consideramos que la feminidad representada en la cerámica, puede estar más bien asociada a una culturización de la mujer como concepto abstracto, es decir, pudo ser concebida cercana a la cultura (aunque no se separa por completo de la naturaleza) al menos en el ámbito de la representación social que el hombre, probablemente representado en otros ámbitos estéticos no necesariamente físicos. $\mathrm{Al}$ contrario de lo que propone Escalante (2007), consideramos que esta asociación de lo femenino con la reproducción no implica necesariamente que la mujer era un ser social controlado por las elites. Tomando en cuenta que Sanoja y Vargas (1974), proponen que la deformación de los cráneos estaba asociada a individuos de un alto estatus y Brites (1994) describe cráneos femeninos deformados en su trabajo, entonces la mujer también podía tener un alto estatus por lo cual ponemos en duda la imagen de la mujer como un ente dominado. En relación a la desnudez no podemos decir que la mujer, estuviese cotidianamente desnuda, aunque no existe documentación de esto.

Como mencionamos anteriormente, asociamos el hecho de que algunas piezas efigie e independiente presenten las manos sobre el rostro como acto de sostener una máscara. Dicha máscara presenta los mismos rasgos que las cabezas con deformación craneal, es decir, de forma alargada o naviforme y decoración inciso-punteada. 
Esta similitud nos abre una pregunta, iporque producir mascaras con aspecto similar al rostro tomando en cuenta que la escarificación en el rostro y la deformación craneal eran practicadas (existen pruebas en el registro arqueológico al menos de esta última)? La respuesta a esta pregunta podría residir en la jerarquización de estos grupos la cual, implica un acceso desigual a los recursos económicos y, porque no, a los recursos estéticos. Tomando como cierta la propuesta de Sanoja y Vargas (1974; 1999. Ver también Vargas 1990), sobre la deformación craneal, estas máscaras (de las cuales desconocemos su contexto de uso, el cual pudo ser meramente ceremonial) otorgarían un parcial y no permanente estatus, aunque no se igualaría en superioridad sino que seria una mediación o un acercamiento simbólico.

Sin embargo, no consideramos la deformación craneal y el uso de la mascara como mutuamente excluyentes o binarios; un individuo de cráneo modificado pudo usar una mascara en ciertos momentos para afianzar su estatus sobre los otros. Es decir, una falsa impresión de estatus social, político, ceremonial, etc., o un reforzamiento del mismo, las mascaras funcionaron como una incorporación del poder. La representación material del poder podía ser circunstancial, mediante el uso de la máscara, o permanente a través de la deformación craneal o la escarificación. Por el contrario, el uso de collares, aretes, etc., debido a que la materia prima osteo-odonto-queratico se obtenía mediante la caza y la pesca en el lago y la costa, por lo cual estaban disponibles directamente sin necesidad del intercambio, no necesariamente representaban objetos suntuarios, como los casos andino y del noroccidente de Venezuela, sin embargo, aunque no descartamos la posibilidad de que existiese una jerarquización en el uso distintivo de collares, narigueras y aretes. Paralelamente en el tiempo a la sociedad valencioide, aunque muy distantes en el espacio, otros grupos jerárquico-cacicales se desarrollaron en el área andina venezolana, como lo son las tradiciones Betijoque y Mirinday.

\author{
$\mathrm{N} \neq \mathrm{H} \neq \mathrm{M}=?^{3}$ \\ La representación antropomorfa \\ tardía en el área andina de Venezuela. \\ Estilos Betijoque y Mirinday
}

Luego de analizar ambos estilos notamos que, posiblemente como consecuencia de la división social del trabajo y el papel de los individuos dentro de una jerarquizada estructura política, la producción cerámica comienza a manifestar una lógica representacional distinta, en la que la figura humana se individualiza tanto en el sentido de separarse del orden artefactual utilitario, lo que no ocurre en las sociedades igualitarias orinoquenses y comienza a gestarse en los grupos jerarquizados valencioides, como de enfatizar los rasgos particulares o específicos de los individuos representados.

También, la figura de lo masculino se hace claramente visible en ambos estilos, aunque no mas profusa que las figuras femeninas y asexuadas. Este fenómeno es único en esta colección en particular, al contrario a las anteriormente analizadas, a partir de la deconstrucción formal e iconográfica de las piezas Betijoque y Mirinday notamos una particular similitud en forma de representar los rasgos corporales y la decoración. Esto, al igual que en las sociedades barrancoide y saladoide, pudo ser consecuencia de una hermandad pantribal consecuencia de la proximidad espacial y temporal que compartían estos grupos andinos. Aunque no estamos sugiriendo que cumplió la misma función que en las culturas orinoquenses tempranas. Lo mismo ocurre con la decoración. Se presentan similitudes en los motivos pintados, pero cada sociedad mantiene elementos identitários particulares, siendo la mayor profusión de piezas con pintura pertenecientes al estilo Betijoque y las piezas de poca o ninguna decoración pintada al estilo Mirinday. Sin embargo, para las sociedades barrancoides y saladoides, la representación simbólica del cuerpo responde a una relación hombre-na-

3 Hace referencia a la relación hombre-naturalezacultura, donde $\mathrm{N}=$ naturaleza; $\mathrm{H}=$ hombre, $\mathrm{M}=\mathrm{Mu}$ jer, $?=$ iasexuado? 
turaleza-cultura, la valencioide a una asociación de lo femenino con lo cultural-natural, para las sociedades andinas responde a dos cosas, por una parte, a la diferenciación entre lo masculino, lo femenino y lo feminizado y, por otro lado, a la relación entre lo sagrado y lo político. En estas sociedades estratificadas se construyó un discurso mediante el cual se igualaron las contradicciones sociales de tal forma que, lo ceremonial y lo estético se unificaron en el proceso de simbolización del poder, la subordinación y la desigualdad social entre individuos y géneros. El poder se reviste de sacralidad y esta sacralidad:

...se expresa en un orden que aparece como necesario y que se legitima con la subordinación (...), haciendo de ella un instrumento de mando. Este principio "ordenador" que tiene el poder, parece tener resonancia no sólo en la organización social, sino también en las manifestaciones estéticas de las sociedades tribales, debido a que muchas de las formas ideológicas del poder suelen vivirse estéticamente... (Delgado 1989: 55).

Como mencionamos, dentro de esta cultura se produce una diferenciación plástica y probablemente conceptual del cuerpo y de la relación representativa sexo/género. Se representan individuos masculinos sedentes sobre un banco, femeninos sedentes sobre si y de pie, ninguno de ellos presenta apéndices como en el caso valencioide. También existen piezas que representan individuos asexuados que, de la misma forma que los grupos jerárquicos de la costa central de Venezuela, se presentan feminizados, es decir, comparten elementos estéticos y simbólicos de las figuras femeninas. Si bien hemos propuesto que en el caso valencioide la feminidad es asociada a lo cultural-natural, además que las piezas asexuadas tienden a ser femeninas (debido a similitudes morfológicas en la representación) y que lo masculino se representa estéticamente en otros medios (físicos o no), ique ocurre en el caso de estas culturas andinas donde lo masculino es claramente representado en la cerámica?. Pareciese que existe una feminización o un acercamiento a lo femenino en las piezas asexuadas. Ahora, poniendo a un lado esto, iacaso estas representaciones figurativas representan individuos (aunque sea de forma conceptual) sin sexo? Probablemente la respuesta sea afirmativa. Estas piezas pueden representan individuos en un estado previo a "alcanzar" un estatus de genero dentro de la sociedad mediante, posiblemente, un ritual de paso como ocurre en culturas contemporáneas y, posiblemente, la feminización de estas piezas es producto de la asociación de estos individuos no adultos o en estado de niñez a la madre o al seno materno de la familia o del grupo, aunque no necesariamente eran exclusivamente las mujeres quienes criaban a los niños. En cuanto a la relación de lo masculino y lo femenino en esta cultura, se denota una gran importancia:

...de la mujer como reproductora de la fuerza de trabajo. Este sustrato económico se recrea, tanto simbólica como estéticamente, en la imagen de la mujer como icono. No obstante, la importancia centralizadora de la actividad económica, política, militar y religiosa que recae sobre la figura del cacique, se reproduce (...) en una iconografía que pone de manifiesto la fuerza y la solemnidad que le confiere el poder (Delgado 1989: 65).

Como se aprecia, la parafernalia representada en piezas Betijoque y Mirinday no implica, con excepción de la perforación del lóbulo, una modificación del cuerpo como en el caso de Valencia. Incluso el tatuaje no involucra un cambio en la naturalidad de la piel y las proporciones corporales como, por ejemplo, lo hacen la escarificación y la deformación craneal intencional.

\section{ConClusión}

Retomemos un poco lo dicho, a manera de conclusión intracultural, para cada una de estas sociedades. Como vimos cada forma de representación responde a la relación entre los individuos de la cultura productora y su ambiente, entre individuos o entre ámbitos sociales como lo político y lo ceremonial. La contradicción principal de los grupos barrancoides y saladoi- 
des era la relación hombre-naturaleza y su incorporación a la cultura pensado estos como un todo indisoluble. Para el caso valencioide, lo contradictorio subyace en la asociación de la feminidad representada en las figuras con la representación cultural (física) de la mujer como un concepto abstracto y naturaleza en forma de apéndices zoo y fitomorfos. Más, sin embargo, la figura humana no es pensada dentro de un sistema natural total. Esto ultimo debido a la importancia del individuo en sistemas políticos estratificados. En cambio, en el caso de las sociedades andinas, existe una marcada separación total entre hombre-naturaleza y, ésta ultima, no se asocia directamente a la cultura. Lo políticoceremonial toma un papel central en las representaciones estéticas del cuerpo. También existe una clara diferenciación entre lo masculino y lo femenino. Sobre esto podemos concluir que las formas o modos de representar al ser social, mediante cuerpos modelados en cerámica, guarda una correspondencia directa con la relación individuo-naturaleza-cultura-sociedad en términos de los modos de vida e ideologías específicas de cada cultura.

En relación al hecho de si en estas sociedades la figuración antropomorfa cerámica refleja prácticas corporales o performatividad de la sociedad a la que pertenecen, podríamos decir que, al menos con la muestra analizada, sólo logramos suponer que las figuras masculinas andinas refieren a actividades rituales, debido a que estas se encuentran mas activas estéticamente que las figuras femeninas, las valencioides y orinoquenses. Dentro de los atributos pictográficos y su relación con la representación del género, la feminización de ciertas piezas clasificadas como asexuadas, en las sociedades de la costa central y Andes opuesta a la representación de lo masculino en el caso Betijoque-Mirinday. En cuanto a la representación del género en cada una de estas culturas podemos decir que, en el caso del Orinoco, las piezas se presentan como asexuales, es decir, no se representa sexo biológico en casi ninguna pieza, lo cual no da un marco comparativo entre los caracteres biológicos, decorativos y de género. Los valencioides, los cuales tampoco representan figuras claramente masculinas, particularmente en cuanto a sus piezas figurativas, podemos definirlos como femeninos, debido a la generificacíon (engendering) de sus representaciones antropomorfas bajo cánones estéticos feminizados. En los Andes, ocurre algo similar entre las representaciones femeninas y asexuadas; sin embargo, aparece la figura masculina proporcionando un patrón estético de comparación por oposición. Esto nos permite definirlos como sexuales, debido a que se crea una división figurativa simbólica entre lo femenino-masculino y hombre-mujer. Ahora, iestos mismos atributos estilísticos de figuración que puedan funcionar como marcador de estatus dentro de cada sociedad? Para el caso barrancoide-saladoide probablemente no tenga cabida esta pregunta debido a que en una sociedad igualitaria no existen estatus sociales más allá de ciertos rangos adquiridos durante ciertos momentos (guerra, ceremonias, etc.) y dentro de la relaciones de parentesco. En cambio, los valencioides y los grupos BetijoqueMirinday denotan una incorporación del poder mediante las representaciones de la deformación craneal intencional-máscaras y las figuras masculinas sedentes sobre un dúho y sosteniendo un bol como representaciones activas de lo político respectivamente. Es decir, a través de las piezas antropomorfas evidenciamos tres relaciones de poder diferentes. Primero un poder cultural-natural en los barrancoides-saladoides, un poder sociocultural en el caso de los valencioides y el poder individual en los Andes.

Por ultimo, a través de la figuración antropomorfa cerámica pudimos observar las modificaciones, alteraciones o intervenciones del y sobre el cuerpo practicadas por los individuos de las distintas sociedades estudiadas, exceptuando las del Orinoco. La tradición valencioide incorpora dentro de sus cánones estéticos la deformación irreversible del cuerpo, mediante la deformación del cráneo desde en nacimiento de los niños, hasta las perforaciones del lóbulo y las escarificaciones en el rostro como una incorporación o inscripción del estatus social y probablemente del concepto de belleza socialmente aceptado y, como veremos, probablemente divulgados. Para 
los Andes ocurre algo diferente. El interés no es deformar el cuerpo, sino informarlo mediante una escritura, probablemente no permanente, a través de la pintura corporal o de forma permanente mediante los tatuajes, los cuales, pueden ser modificados con otros tatuajes o sobre escritos con pintura en ciertos momentos o, incluso, la decoración quizás nunca estuvo sobre algún cuerpo sino que se inscriben sobre la representación cerámica para señalar cierto tipo de incorporación social, como la pertenencia a un grupo especifico. Esto, aparte de responder a cánones estéticos de lo bello, pudo estar asociado al sistema cosmogónico igualmente aceptado y divulgado en la sociedad. Igualmente, no descartamos que probablemente ciertas cuestiones decorativas respondieran a decisiones estilísticas. Dichos acuerdos estilísticos pudieron ser: (i) Normativos, es decir impuestos por la sociedad. (ii) Funcionales, por ejemplo, en el caso de sostener la mascara, pudo ser, al contrario de lo que nosotros suponemos, realmente un soporte estructural. (iii) Simbólicos, queriendo representar acciones o sentimientos, volviendo al caso de las manos, el hecho de representarlos sobre el rostro o en la cintura pudo tener significados antagónicos. (iv) Representacionales, es decir, la figura en realidad sostiene una mascara. (v) Por ultimo, individuales, teniendo el o la artesana el libre albedrio de colocar las manos en el rostro o en las caderas, representarlas sedentes o de pie, sexuada o asexuada.

Estas piezas figurativas pudieron cumplir un papel importante en la divulgación de un mensaje político, ideológico, ceremonial y porque no estético, en relación a la construcción del ser social, así como en la sociedad moderna, las muñecas juegan un rol para el aprendizaje (inconsciente) en niños (y también en adultos) de las relaciones de género, jerarquías sociales, lo estética y conductualmente aceptado, etc. De hecho, como constituyente en la definición individual de la persona social, las muñecas o muñecos aportan sin el menor esfuerzo una imagen previamente convenida que dicta, por ejemplo, la ropa o el comportamiento sexual socialmente apropiado (Bailey 2005: 70). En relación a esto, proponemos que las piezas figurativas andinas y valencioides, mediante la manipulación, son formas expresión y contemplación de la identidad socialmente promulgada y aceptada por la sociedad en la que estas fueron producidas y utilizadas; por ello la importancia de la miniaturización del cuerpo socializado. Estas figuras simplificaban cada uno de los microcosmos simbólicos, estéticos e ideológicos y abrían un mundo de relaciones tan extenso y complejo que de otra forma sería virtualmente inasible. No suponemos estas páginas como conclusiones, sino como una diáspora epistemológica que abre el camino a más preguntas sobre la interpretación de estas piezas en su contexto social, de producción y reproducción. Sin embargo, estas proposiciones sientan una base teórico-metodológica para la compresión fenómenos estético-figurativos del pasado prehispánico venezolano, los cuales son poderosos vehículos utilizados por la sociedad para proponer, negociar, interactuar o cuestionar identidades personales o comunales, donde el cuerpo está lleno de intencionalidad y significados en su representación material.

\section{Bibliografía}

Antczak, M. y A. Antczak

1999 "La esfera de interacción Valencioide". En Arte Prehispánico de Venezuela. Editores Miguel Arroyo, Lourdes Blanco y Erika Wagner. Galería de Arte Nacional, Caracas.

2006 Los ídolos de las islas prometidas. Arqueología prehispánica del archipiélago de Los Roques. Editorial Equinoccio, Caracas.

Antolinez, Gilberto

1941 "Arqueología comparada. Figuración del otro yo en nuestro arte prehispánico". En El agujero de la serpiente. Gilberto Antolinez. Obras Vol. II. Editor Orlando Barreto (1998). Ediciones de la Oruga Luminosa. Colección de Voces Secuestradas, San Felipe.

Bailey, Douglass

2005 Prehistoric figurines. Representation and corporeality in the Neolithic. Routledge, Londres. 
Cruxent, José M. e Irving Rouse

1958 Arqueología cronológica de Venezuela. 2 vols. Ernesto Armitano Editor, Venezuela.

\section{Escalante, Nancy}

2007 Análisis del concepto histórico del cuerpo femenino dentro de los cacicazgos Valencia (1200 - 1300 d.C.). Trabajo final de grado para optar por el titulo de Antropólogo. UCV.

Kottak, Conrad

2003 Espejo para la humanidad. Introducción a la antropología cultural. McGraw-Hill, Madrid.

Levi-Strauss, Claude

1964 El pensamiento salvaje. Fondo de Cultura Económica, México.

Navarrete, Rodrigo

1999 "El Orinoco medio". En Arte Prehispánico de Venezuela. Editores Miguel Arroyo, Lourdes Blanco y Erika Wagner. Galería de Arte Nacional, Caracas.

2006 Nosotros y los otros. Aproximación teóricometodológica al estudio de la expresión de la etnicidad en la cerámica de las sociedades barrancoide y ronquinoide en el bajo y medio Orinoco (600 a.C.-300 d.C.). Monte Ávila editores, Caracas.

Rouse, Irving y Jose M. Cruxent

1963 Arqueología Venezolana. IVIC, Caracas.
Sanoja, Mario

1981 Los hombres de la yuca y el maíz. Un ensayo sobre el origen y desarrollo de los sistemas agrarios en el mundo. Monte Ávila Editores, Caracas.

2006 Memorias para la integración. Ensayo sobre la diversidad, la unidad histórica y el futuro político de Sudamérica y el Caribe. Monte Ávila Editores, Caracas.

Sanoja, Mario e Iraida Vargas

1974 Antiguas formaciones y modos de producción venezolanos. Monte Ávila, Caracas.

1999 Orígenes de Venezuela. Regiones geohistóricas aborígenes hasta 1500 d.C. Comisión Presidencial V centenario de Venezuela, Caracas.

Tarble, Kay

1988 "Prehispánico. Mesoindio: 5000 a.C. 1000 a.C." En Diccionario Fundación Polar, Vol. 3. Fundación Polar, Caracas.

Vargas, Iraida

1990 Arqueología, ciencia y sociedad. Ensayo sobre la teoría arqueológica y la formación económico social tribal en Venezuela. Editorial Abre Brecha, Caracas.

Wagner, Erika

1999 "La región andina". En Arte Prehispánico de Venezuela. Editores Miguel Arroyo, Lourdes Blanco y Erika Wagner. Galería de Arte Nacional, Caracas. 